\title{
Environmental Engineering, Atmosphere
}

National Cancer Institute

\section{Source}

National Cancer Institute. Environmental Engineering, Atmosphere. NCI Thesaurus. Code C18763.

Environmental eng ineering focusing on issues related to air quality management and remediation. 